\title{
The Usefulness of Modified Mallampati Score and CT Upper Airway Volume Measurements in Diagnosing OSA among Patients with Breathing-Related Sleep Disorders
}

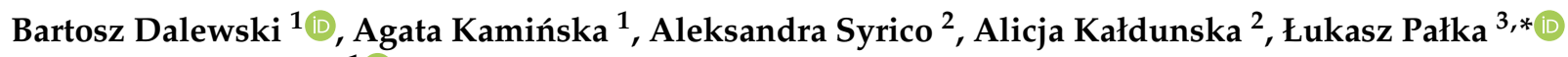 \\ and Ewa Sobolewska ${ }^{1}$ (D) \\ 1 Chair and Department of Dental Prosthetics, Pomeranian Medical University, 70-110 Szczecin, Poland; \\ bartosz.dalewski@pum.edu.pl (B.D.); agata.kaminsk@gmail.com (A.K.); rpsobolewski@wp.pl (E.S.) \\ 2 Student Research Club of Dental Prosthetics, Pomeranian Medical University, 70-204 Szczecin, Poland; \\ a.syrico@gmail.com (A.S.); alakaldunska@gmail.com (A.K.) \\ 3 Private Dental Clinic, 68-200 Żary, Poland \\ * Correspondence: dr.lpalka@gmail.com; Tel.: +48-608-88-25-35
}

check for updates

Citation: Dalewski, B.; Kamińska, A.; Syrico, A.; Kałdunska, A.; Pałka, Ł.; Sobolewska, E. The Usefulness of Modified Mallampati Score and CT Upper Airway Volume Measurements in Diagnosing OSA among Patients with Breathing-Related Sleep Disorders. Appl. Sci. 2021, 11, 3764. https://doi.org/10.3390/app11093764

Academic Editor: Antonio Scarano

Received: 22 February 2021

Accepted: 19 April 2021

Published: 22 April 2021

Publisher's Note: MDPI stays neutral with regard to jurisdictional claims in published maps and institutional affiliations.

Copyright: (c) 2021 by the authors. Licensee MDPI, Basel, Switzerland. This article is an open access article distributed under the terms and conditions of the Creative Commons Attribution (CC BY) license (https:// creativecommons.org/licenses/by/ $4.0 /)$.

\begin{abstract}
Background: Obstructive sleep apnea (OSA) is a condition causing restriction of the airflow through the upper airways during sleep, despite preserved inspiratory muscle activity. This may lead to the development of secondary hypertension, ischemic heart disease, myocardial infarction, and arrhythmia. Moreover, the prevalence of OSA is on the rise. Methods: Comparison of scores from the Berlin Questionnaire, modified Mallampati scores (MMP), pulse oximetry readings and Upper Airway Volume (UAV) data obtained from CBCT (Cone Beam Computed Tomography). The study group of 129 patients of both sexes reporting sleep-related breathing problems completed the Berlin Questionnaire, had their oxygen saturation (SpO2) measured with a PO40 pulse oximeter, and oropharyngeal tissues assessed according to MMP. CBCT scans were put into 3D Amira TM 3D computer analysisto obtain UAV values. Results: Snoring was associated with significantly higher BMI compared to non-snoring patients. Furthermore, snoring patients had higher heart rate, modified Mallampati score, and lower UAV than the non-snoring group. The multifactorial analysis showed MMP as a useful indicator of the risk of snoring $(\mathrm{OR}=7.468(3863-14,507, p<0.001)$. Conclusions: The composition of MMP together with UAV and the Berlin questionnaire might be reliable indicators to assess the risk of snoring.
\end{abstract}

Keywords: obstructive sleep apnea; modified Mallampati; airways; Berlin Questionnaire; snoring; oxygen level; CBCT

\section{Introduction}

Breathing-related sleep disorders are breathing abnormalities, including habitual snoring, upper airway resistance syndrome (UARS), and obstructive sleep apnea (OSA) [1]. Snoring is a harsh and buzzing noise produced by the vibration of the respiratory structures, primarily with inspiration during sleep. When it is present at least three nights per week, it may be associated with OSA [2]. It is characterized by repeated episodes of complete or partial obstruction of the upper airways during sleep, with preserved inspiratory muscle activity [3-5]. As a result ofa decrease in blood oxygenation (with SpO2 levels down 2-4\%) hypoxemia may be observed not only during the night but daytime as well [6-11]. Additionally, it may cause increased drowsiness, morning headaches, problems with concentration and memory, loss of libido, and depression [12-15]. It affects $24 \%$ of males and $9 \%$ of females in the adult population [2,13]. Men aged 40-70 and postmenopausal women are at the highest risk for developing OSA [16]. According to the literature, predisposing factors for OSA include: overweight and obesity (found in 70\% of patients with confirmed OSA), neck circumference $\geq 43 \mathrm{~cm}$ for men and $\geq 40 \mathrm{~cm}$ for women, anatomical alterations 
in the upper respiratory tract, i.e., an elongated soft palate and/or uvula, palatine tonsil hypertrophy, nasal septum curvature, nasal turbinate hypertrophy; endocrine disorders such as hypothyroidism and acromegaly; mandibular development disorders (micro-, macrognathia); use of sedatives, hypnotics; alcohol consumption (especially at bedtime) and smoking [17]. Underdiagnosed or untreated sleep apnea may lead to the development of secondary hypertension (in more than $50 \%$ of patients), ischemic heart disease and myocardial infarction, arrhythmia and conduction disorders, heart failure, stroke, and transient ischemic attacks, pulmonary hypertension, and upper airway resistance syndrome, gastroesophageal reflux disease, depression, impaired glucose tolerance (type II diabetes), metabolic syndrome, and even sudden death [18].

To avoid these life-threatening complications and for financial reasons, it is crucial to identify patients with high risk for OSA at an early stage. The primary care physician or dentist should use simple and repeatable screening tools for OSA risk assessment and subsequently refer them to more expensive and time-consuming polysomnography as the gold standard for OSA diagnosis [19]. The aim of this study was to estimate the usefulness and value of combined diagnostic tools like modified Mallampati scores (MMP) and upper airway volume (UAV) in diagnosing high risk OSA among patients reporting breathing problems during sleep treated in the Prosthetics Outpatient Clinic, Pomeranian Medical University in Szczecin, Poland. Additionally, we aimed to develop the simplest and fastest possible screening method that could be used routinely to identify high risk-OSA patients.

\section{Materials and Methods}

The included study group consisted of 129 Caucasian patients ( 99 females aged $43.78 \pm 12.89$ and 30 males aged $45.37 \pm 17.41$ ) who reported sleep-related breathing problems to the Dental Prosthetics Outpatient Clinic, Pomeranian Medical University in Szczecin. The exclusion criteria were as follows: 16 years of age or less, pregnancy, unstable cardiovascular diseases, neurological conditions affecting breathing muscles, moderate to severe respiratory disease or inability to provide reliable information consent or information according to questionnaire, e.g., psychiatric or psychological conditions. The $B Q$ was issued at the time of the patient's initial appointment by a trained examiner (B.D.). Patient's family or bed partner were asked to confirm the accuracy of the responses to the questions. Collected data were analyzed and stored at the Department of Dental Prosthetics. Subsequently, their oxygen saturation (SpO2) was measured with a PO40 pulse oximeter (Beurer, Ulm, Germany), and their oropharyngeal space was assessed according to the modified Mallampati classification. The questions in Berlin Questionnaire are divided into three categories: the first five relate to sleep (presence/absence of snoring, its frequency, and intensity, observation of pauses in breathing), the following 4 questions are used to determine the degree of daytime sleepiness, and the last question refers to the presence of concomitant hypertension [20]. The modified Mallampati classification is used to assess oropharyngeal space. The score reflects the position of the tongue relative to the soft palate and uvula [21]. It is assessed by asking the patient to open their mouth as wide as possible and protrude their tongue as much as possible, without making any sounds. Based on the assessment of the visible structures, the patient will fall into one of four categories:

Class I soft palate and uvula fully visible;

Class II soft palate and major part of uvula visible;

Class III soft palate and base of uvula visible;

Class IV soft palate not visible.

In addition, each patient was referred for cone beam computed tomography (CBCT, iCAT, Imaging Sciences, Hatfield, PA, USA, FOV: $16 \times 13 \mathrm{~cm}, 0.25 \mathrm{~mm}$ voxel, scanning time $26.9 \mathrm{~s}$ ). All CBCT scans were acquired by the same calibrated examiner to ensure the repeatable conditions, including head and tongue posture [22,23]. Every patient's data obtained from CBCT scans were then uploaded into the 3D Amira ${ }^{\mathrm{TM}}$ visualization and analysis computer program (Thermo Fisher Scientific, Berlin, Germany) and set on 
cephalogram shot to calculate upper airway volume (UAV). Four landmarks were used, such as posterior nasal spike, the tip of the uvula, the top of the epiglottis, and the base of the epiglottis. The program marked the airways from which the upper airway volume was extracted (based on the landmarks). Mapping from 2D to 3D through interpolation was made to receive the volumetric measure automatically. The details, including landmarks used in the measurements and upper airway volume view in Amira are presented in Figures 1 and 2.

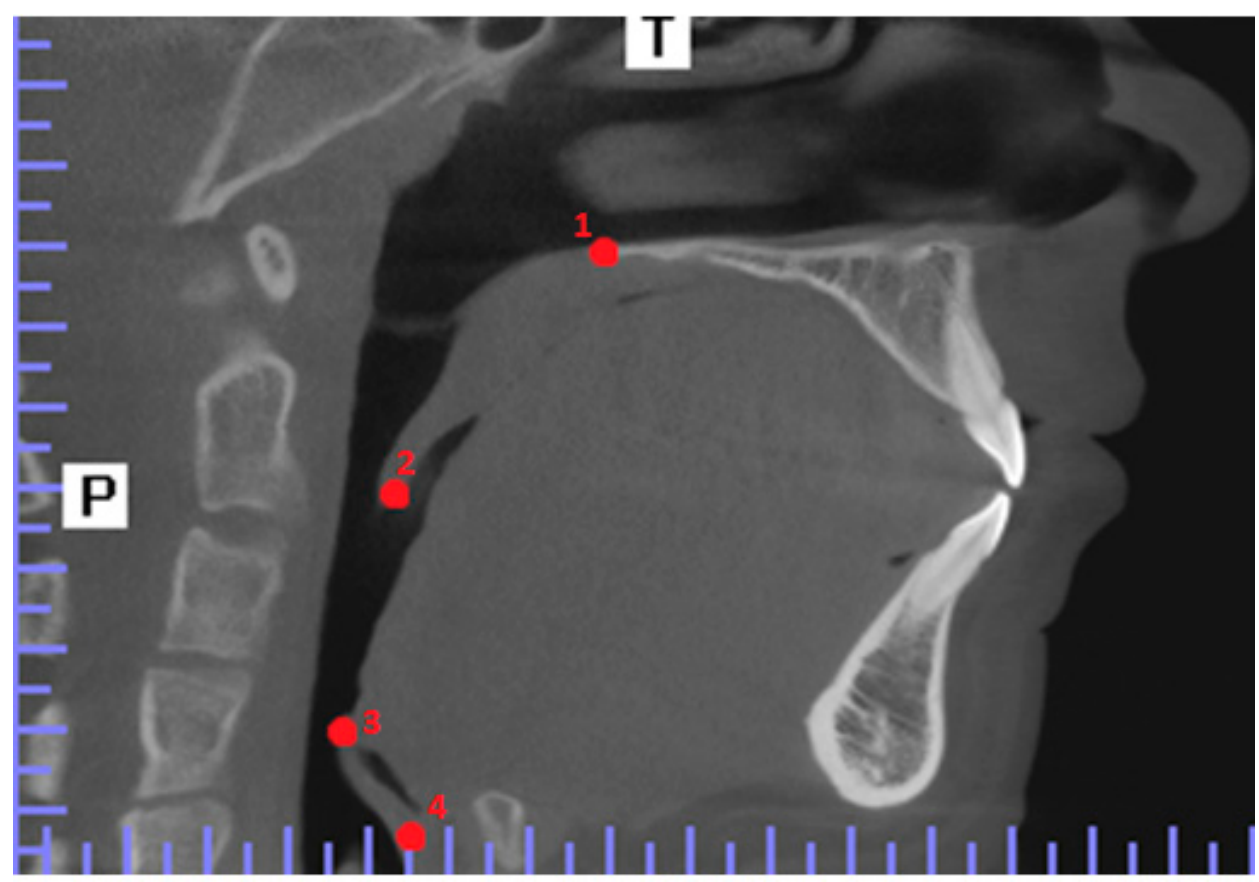

Figure 1. Landmarks used in CBCT analysis: posterior nasal spike (1), the tip of the uvula (2), the top of the epiglottis (3), the base of the epiglottis (4).

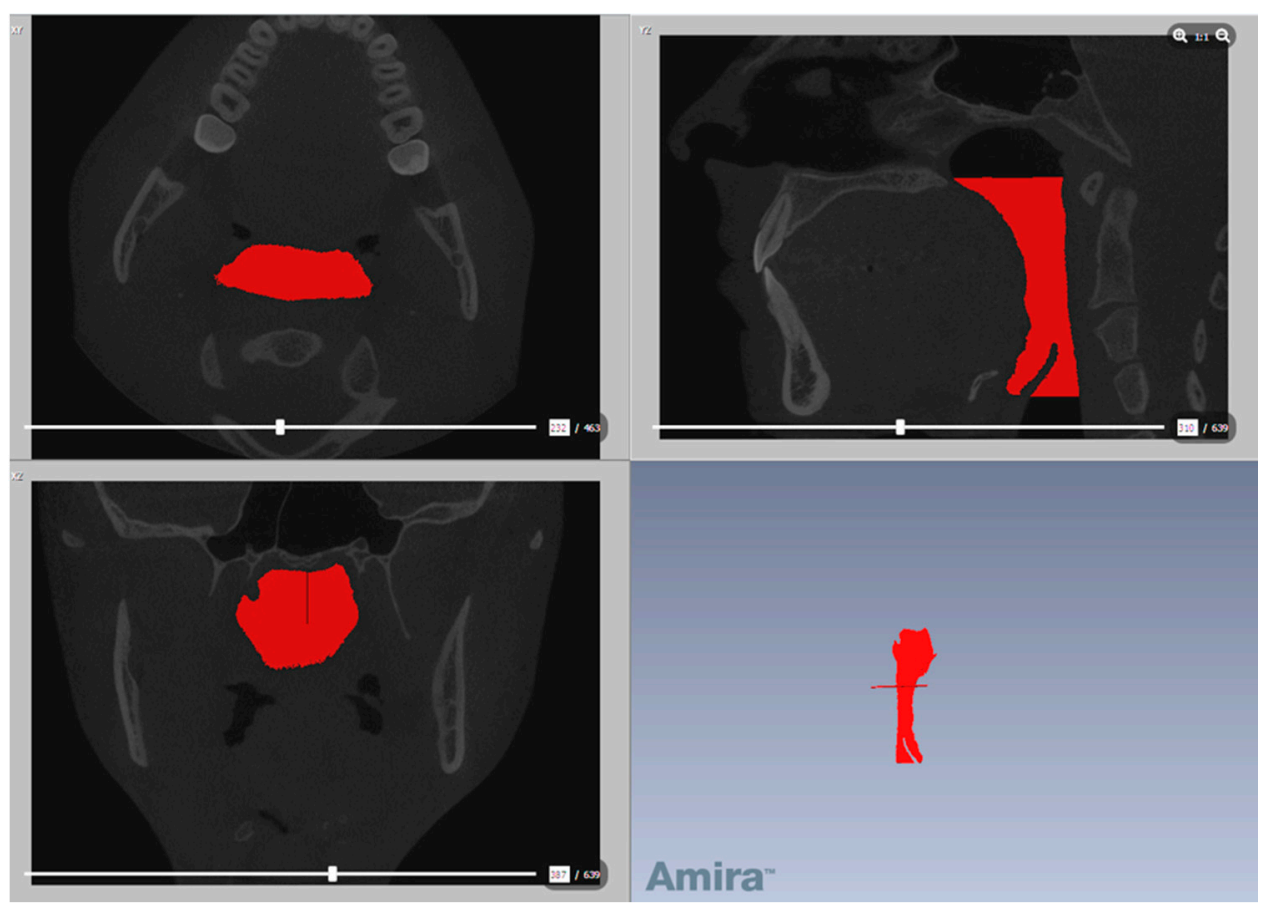

Figure 2. The volumetric measure of upper airways using Amira ${ }^{\mathrm{TM}}$. 
To check the normality of data distribution, the Shapiro-Wilk test was used. Variables with normal distribution are presented as a \pm mean with a standard deviation. Variables with non-normal distribution are presented as a median with an interquartile range (Tables 1 and 2).

Table 1. Correlation between sex and mean age and BMI.

\begin{tabular}{|c|c|c|c|c|}
\hline & Yes $(n=69)$ & No $(n=47)$ & $\begin{array}{l}\text { Do Not Know }(n= \\
\text { 13) }\end{array}$ & $p$ \\
\hline BMI & $26.14 \pm 4.03$ & $23.75 \pm 3.87$ & $22.76 \pm 3.71$ & $<0.001$ \\
\hline SpO2 & 98 (97-98) & 99 (98-99) & 98 (97-99) & $<0.001$ \\
\hline $\mathrm{HR}$ & $74(68-80)$ & 68 (64-77) & $69(63-74)$ & 0.004 \\
\hline MMP & $3(3-4)$ & $1(1-2)$ & $2(2-2)$ & $<0.001$ \\
\hline UAV & $\begin{array}{c}13,241.4 \\
(10,862.7-16,947.3)\end{array}$ & $\begin{array}{c}17,627.4 \\
(12,650.3-22,572.5)\end{array}$ & $\begin{array}{c}17,174.5 \\
(14,839.0-20,483.7)\end{array}$ & $<0.001$ \\
\hline
\end{tabular}

Table 2. Values of the variables included in the analysis depending on the answer to the question "Do you snore?" in the Berlin Questionnaire.

\begin{tabular}{ccc}
\hline Parameter & OR & $p$ \\
\hline Age & $1.004(0.978-1.031)$ & 0.76 \\
Gender & $1.687(0.729-3.904)$ & 0.22 \\
BMI & $1.172(1.055-1.301)$ & 0.0031 \\
MMP & $7.486(3.863-14.507)$ & $<0.001$ \\
UAV & $0.998(0.997-0.999)$ & $<0.001$ \\
\hline
\end{tabular}

Variables with a normal distribution were compared using ANOVA variance analysis, Kruskal-Wallis non-parametric test, and posthoc multiple comparison test with the Tukey post hoc test. The estimated power for comparison of the three groups at effect size $=0.5$ was 0.99 (G*Power software, Düsseldorf, Germany) (Figure 3). In order to estimate the correlation between the variables, Spearman's and Kendall's correlation coefficients were used. In order to estimate the correlation between variables, Spearman's correlation coefficient was used. The chi-square test was carried out for the qualitative evaluation of variables. A logistic regression model was created to assess hidden risk. The results of univariate analysis are represented as an odds ratio with a $95 \%$ confidence interval. Multivariate analysis was performed using the stepwise regression method. The significance level was adopted as $\alpha=0.05$. The study was approved by the Bioethics Committee of Pomeranian Medical University in Szczecin (approval number KB-0012/83/16) and was conducted in accordance with the Declaration of Helsinki and Good Clinical Practice set forth by the International Conference on Harmonization of Technical Requirements for Registration of Pharmaceuticals for Human Use (ICH). We also ensured that the study conformed to applicable international regulatory authority laws, regulations, and guidelines. 


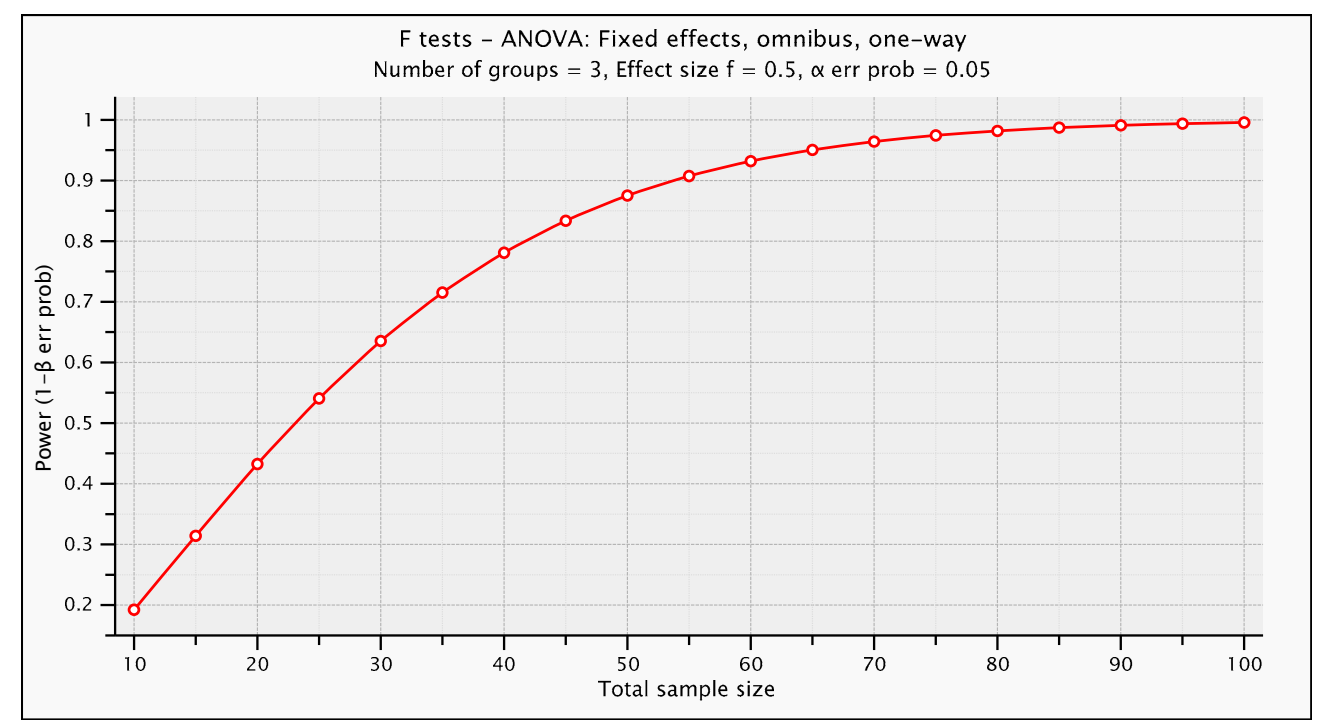

Figure 3. Sample size determination.

\section{Results}

The mean age in the women's group was $43.78 \pm 12.89$ years and in the men's group, $45.37 \pm 17.41$ years. The average BMI in the women's group was $24.58 \pm 4.27$, the average BMI in the men's group was $26.08 \pm 3.43$ (Table 1). In response to question 1 of the Berlin Questionnaire (Do you snore?) 69 patients answered "yes" (54 females, 15 males), 47 (32 females, 15 males) "no", and 13 patients did not know if they snored (13 females). We did not find gender-related risks of developing OSA (Figure 4). Patients who reported snoring also reported increased fatigue after waking up, as well as increased daytime sleepiness, compared to non-snorers who answered, "I am never or nearly never tired during the day". Significantly higher BMI scores ( $26.14 \pm 4.03$ vs. $23.75 \pm 3.87)$ were observed in declared snorers compared to non-snoring patients (Figure 5). In addition, snoring patients had higher Heart Rate (74 bpm vs. $68 \mathrm{bpm}$ ), higher modified Mallampati score (3 vs. 1) and lower UAV (13,241.4 vs. 17,627.4 vx) than the non-snoring group. Further analysis showed that snoring affects men and women equally. There were significant differences in blood oxygenation in snoring compared to non-snoring patients-98 vs. 99. In our study, breathing-related problems coincided with BMI ranging from 16.60 and higher, MMP 3 and 4, also UAV value from 5411.78 to $28,337.90 \mathrm{~mm}^{3}$. Additionally we found significant correlation between MMP scale and UAV (Tau $=0.17, p=0.02$ ).

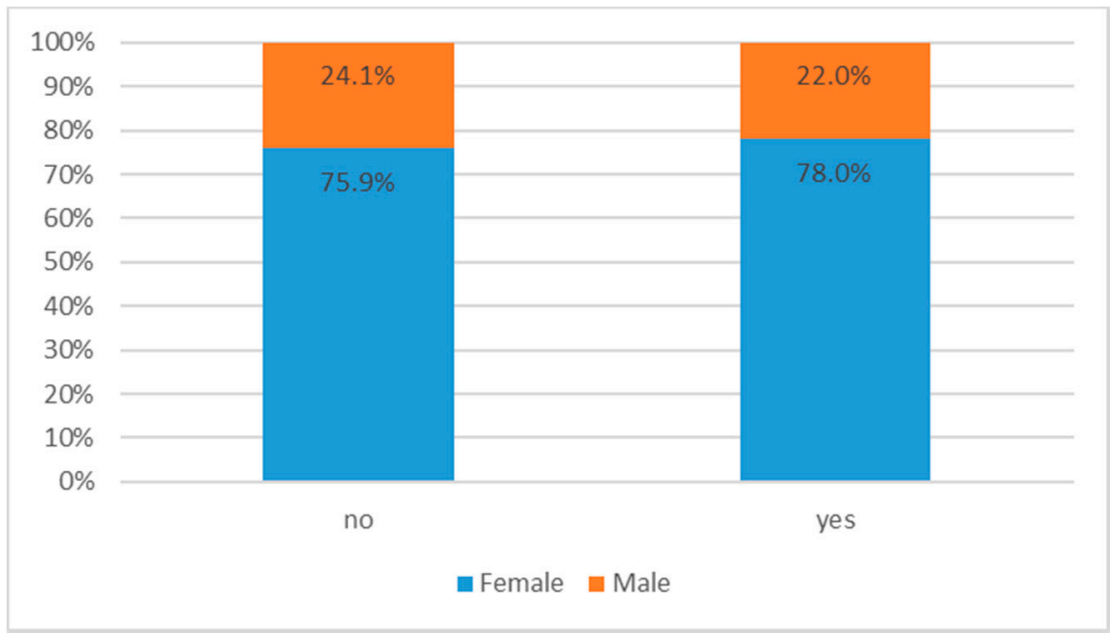

Figure 4. Occurrence of snoring among men and women. P-0.84, Chi^2test. 


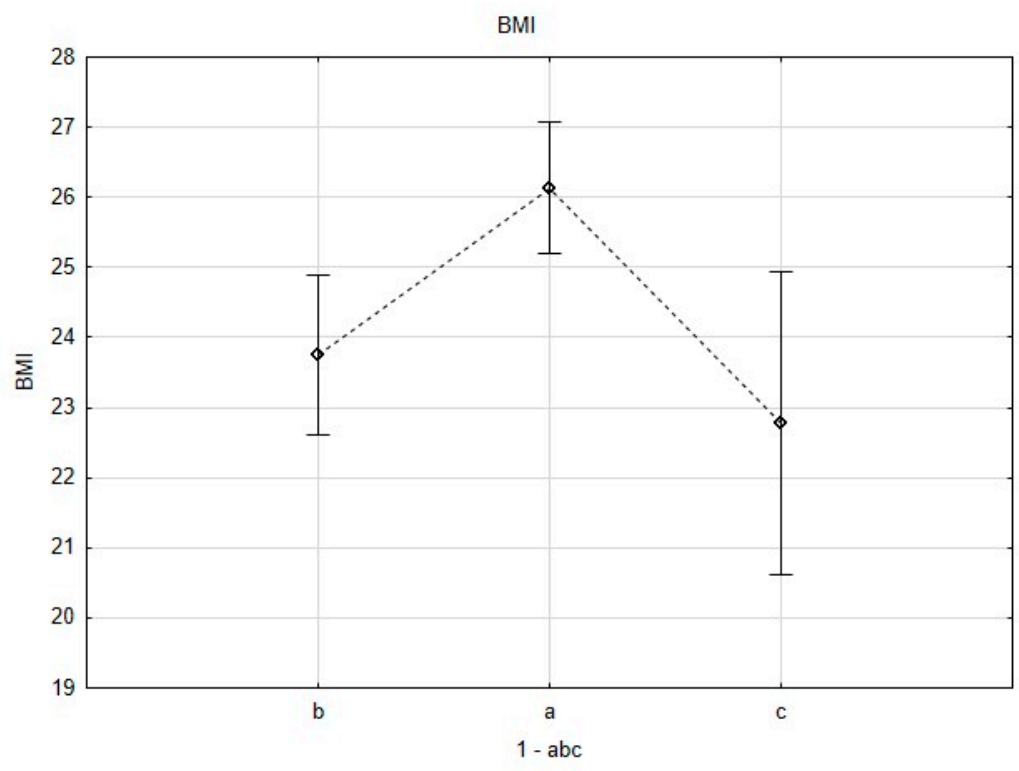

Figure 5. Significantly higher BMI scores (26.14 \pm 4.03 vs. $23.75 \pm 3.87)$ were observed in declared snorers (a) in comparison to non-snoring patients (b and c).

The results are presented in Table 2. No statistically significant differences were observed between snoring and non-snoring patients in terms of daytime fatigue or nodding off/falling asleep while driving a vehicle (questions 7 and 8 of the Berlin Questionnaire). Multifactorial analysis presented in Table 3 showed MMP as a useful indicator in the assessment of the risk of snoring (OR $=7.468(3863-14.507, p<0.001)$ ).

Table 3. Multifactorial logistic regression analysis.

\begin{tabular}{cccc}
\hline Parameter & Males & Females & $p$ \\
\hline Age & $45.37 \pm 17.41$ & $43.78 \pm 12.89$ & $>0.05$ \\
BMI & $26.08 \pm 3.43$ & $24.58 \pm 4.27$ & $>0.05$ \\
\hline
\end{tabular}

\section{Discussion}

The Berlin Questionnaire was initially used as a screening survey for sleep related breathing disorders by Enciso et al. Its sensitivity, specificity, positive and negative predictive value in reference to polysomnography derived data amounted to $67.4 \%, 52.9 \%, 66.0 \%$ and $54.5 \%$, respectively [24]. In our study, breathing-related problems coincide with higher BMI scores, higher MMP, and lower UAV. Furthermore, it is noteworthy that significantly higher MMP score and BMI correlate with significantly lower SpO2 and UAV. The Mallampati scale is a simple four-grade score that can also support physician assessment of patient's UAV, as a part of the physical examination prior to a polysomnography referral [25]. This score and the presence and severity of OSA correlation suggest its practical value in clinical settings and prospective studies of sleep-disordered breathing. However, it was not previously associated with UAV, whereas our study showed statistically significant correlation between MMP 3 and 4 and lowered UAV as measured radiographically. Yet, our findings are in partial opposition to the work of Yanru Li et al. who failed to confirm a direct relationship between BMI and the risk of OSA. Their MRI and CT study revealed that fats deposited around the upper airways, together with total soft tissues volume, indicate increased retroglossal and retropalatal collapsibility. However, this finding turned out to be valid for both patients with OSA and the control group [26]. This may be due to differences in body composition of the patients included in their study, e.g., people with an increased percentage of lean mass-athletes have higher BMI scores, which does not reflect the amount of body fat or indicate an increased risk of OSA. It should therefore be considered 
whether future studies would benefit from the use of the WHR (waist-hip ratio) instead of the BMI index [27]. Zimmerman et al. were the first to evaluate the reliability of the upper pharyngeal airway using $\mathrm{CBCT}$ in 10 patients, concluding that $\mathrm{CBCT}$ might be a valid and reliable tool to evaluate upper airway dimensions in the future [28]. Mouhanna-Fattal et al. evaluated 3D characteristics of UAV and craniofacial volumetric structures in OSA adult patients [29]. The control group included healthy adults with no sleep disorders, according to Epworth sleepiness scale and the Berlin questionnaires. The data obtained from this investigation are consistent with our results - the mean value of UAV in the OSA group was smaller than in the control group, while the post-hyoid volume, posterior volume, and their ratio over total volume were larger than in the control group. The anatomical dimensions of the upper respiratory tract in correlation to the prevalence of sleep apnea were examined by Barrera et al. [30]. In their study, the measurements were based on CBCT and MRI imaging, including soft palate thickness, distance from the mandible plane to the hyoid bone, posterior airway space, and tongue volume. The study showed significantly longer mandibular-hyoid distance, smaller posterior airway space, and larger tongue volume in OSA patients compared to the control group (non-OSA patients). Their results are consistent with the present findings. With regard to the differences in the UAV, our findings also coincide with those observed by Buchanan et al. [31] who used CBCT data to measure UAV in OSA patients. They found that OSA patients had a lower UAV in relation to healthy individuals. Chiu et al., in their 2018 study, analyzed airway resistance during expiration in OSA patients compared to a control group [32]. Expiratory resistance (EXR) in the OSA group was significantly higher $(p=0.04)$. Moreover, the authors observed a statistically significant negative correlation between EXR and the minimum cross-sectional area of the oropharynx $(r=-0.41, p=0.02)$, and between EXR and the oropharynx volume $(r=-0.48, p=0.01)$ in OSA patients. Yucel et al. studied changes in the upper airway cross-sectional area of patients with varying degrees of severity of OSA. Their findings include significantly lower values (narrower cross-sectional area) at the level of uvula in expiration, lower positioning of the hyoid bone and thicker soft palate in patients with severe OSA compared to patients with mild/moderate OSA $(p<0.05)$ and the control group [33]. According to Parsi et al. each millimeter of the mandibular advancement during bimaxillary surgery led to a significant increase in the oropharyngeal volume, while every millimeter downwards reposition resulted in a statistically significant increase in the nasopharyngeal volume [34]. The reliability of upper airway volume analysis based on CBCT studies was investigated by Mattos et al. UAV measurements based on CBCT scans showed high intraexaminer and interexaminer reliability (93\% and 73\%, respectively) [35]. Additionally, our findings are similar with those of Chaudhry et al., who described minimal retropalatal area in concordance with higher STOP-Bang scores, whose questionnaire is also a validated screening tool to identify OSA patients. They concluded that CBCT images where the minimal retropalatal area is smaller than $110 \mathrm{~mm}^{2}$ might indicate patients who are at risk for developing OSA. Hence, airway measurements obtained from CBCT images and STOP-Bang questionnaire scores may be used to increase referrals to a sleep lab [36]. The present study showed statistically significant differences in oxygen blood saturation, which is in agreement with Barrera's study, which noted a difference in saturation between OSA patients $(94.6 \pm 2.3)$ and the control group $(87.7 \pm 7.1 \%)[30]$.

The limitation of our study is the fact that it based on questionnaire-reported sleep disorders without confirmation of OSA diagnosis using polysomnography. The sensitivity of $\mathrm{BQ}$ ranges from $56 \%$ to $84 \%$, specificity $38-59 \%$ [32]. For logistical reasons, we also measured in the study group the daytime $\mathrm{SpO} 2$ level instead of night-time $\mathrm{SpO} 2$, which seems to be more reliable. The other limitation may be associated with UAV measurement. Even though the Amira software was used to determine UAV, the landmarks were plotted in CBCT manually. 


\section{Considerations and limitations of the study}

The multidisciplinary approach to OSA is strongly suggested with a team made up of dentists, ENT specialists and medical experts in sleep disorders. Home sleep apnea testing is less expensive than polysomnography and increasingly used to diagnose OSA. The examination of the upper airway may identify anatomic abnormalities, such as nasal septum deviation, tonsillar hypertrophy and macroglossia, but normal upper airway examination findings do not exclude OSA.

\section{Conclusions}

Higher Mallampati score together with smaller upper airways in CBCT and higher $\mathrm{BMI}$ were found to be correlated with snoring. According to our findings, despite some limitations, the composition of MMP together with UAV and the Berlin questionnaire might be effective indicators of the risk of snoring, thus present as a reliable screening test of OSA. Polysomnography should be considered in patients with a high-risk score.

Author Contributions: Conceptualization, B.D.; methodology, B.D.; software, A.S.; validation, A.K. (Agata Kamińska), B.D. and A.K. (Alicja Kałdunska); formal analysis, Ł.P., and E.S.; investigation, B.D.; resources, A.K. (Alicja Kałdunska); data curation, B.D.; writing-original draft preparation, B.D., A.K. (Agata Kamińska), A.S., writing—review and editing, A.K. (Agata Kamińska), A.S., Ł.P.; visualization, A.S.; supervision, Ł.P., and E.S.; project administration, B.D.; funding acquisition, E.S. All authors have read and agreed to the published version of the manuscript.

Funding: This research received no external funding.

Institutional Review Board Statement: The study was conducted according to the guidelines of the Declarationof Helsinki, and approved by the Bioethics Committee of Pomeranian Medical University in Szczecin (approval number KB-0012/83/16).

Informed Consent Statement: Informed consent was obtained from all subjects involved in the study.

Data Availability Statement: The data presented in this study are available on request from the corresponding author. The data are not publicly available due to sensitive information.

Conflicts of Interest: The authors declare no conflict of interest.

$\begin{array}{ll}\text { Abbreviations } \\ \text { CBCT } & \text { Cone Beam Computed Tomography } \\ \text { CPAP } & \text { constant positive airway pressure } \\ \text { HS } & \text { Habitual snoring } \\ \text { MMP } & \text { Modified Mallampati } \\ \text { OSA } & \text { obstructive sleep apnea } \\ \text { UARS } & \text { upper airway resistance syndrome } \\ \text { UAV } & \text { upper airway volume } \\ \text { WHR } & \text { waist-hip ratio }\end{array}$

\section{References}

1. Tsara, V.; Amfilochiou, A.; Papagrigorakis, J.M.; Georgopoulos, D.; Liolios, E.; Kadiths, A.; Koudoumnakis, E.; Aulonitou, E.; Emporiadou, M.; Tsakanikos, M.; et al. Guidelines for diagnosing and treating sleep related breathing disorders in adults and children (Part 3: Obstructive sleep apnea in children, diagnosis and treatment). Hippokratia 2010, 14, 57-62. [PubMed]

2. Young, T.; Palta, M.; Dempsey, J.; Skatrud, J.; Weber, S.; Badr, S. The Occurrence of Sleep-Disordered Breathing among MiddleAged Adults. N. Engl. J. Med. 1993, 328, 1230-1235. [CrossRef] [PubMed]

3. Eckert, D.J.; Malhotra, A. Pathophysiology of adult obstructive sleep apnea. Proc. Am. Thorac. Soc. 2008, 5, 144-153. [CrossRef]

4. Patil, S.P.; Schneider, H.; Schwartz, A.R.; Smith, P.L. Adult obstructive sleep apnea: Pathophysiology and diagnosis. Chest 2007, 132, 325-337. [CrossRef]

5. Osman, A.M.; Carter, S.G.; Carberry, J.C.; Eckert, D.J. Obstructive sleep apnea: Current perspectives. Nat. Sci. Sleep 2018, 10, 21-34. [CrossRef]

6. Bady, E.; Achkar, A.; Pascal, S.; Orvoen-Frija, E.; Laaban, J.P. Pulmonary arterial hypertension in patients with sleep apnoea syndrome. Thorax 2000, 55, 934-939. [CrossRef] 
7. Chaouat, A.; Weitzenblum, E.; Krieger, J.; Ifoundza, T.; Oswald, M.; Kessler, R. Association of chronic obstructive pulmonary disease and sleep apnea syndrome. Am. J. Respir. Crit. Care Med. 1995, 151, 82-86. [CrossRef]

8. Bradley, T.D.; Rutherford, R.; Grossman, R.F.; Lue, F.; Zamel, N.; Moldofsky, H.; Phillipson, E.A. Role of daytime hypoxemia in the pathogenesis of right heart failure in the obstructive sleep apnea syndrome. Am. Rev. Respir. Dis. 1985, 131, 835-839. [CrossRef]

9. Sanner, B.M. Pulmonary Hypertension in Patients With Obstructive Sleep Apnea Syndrome. Arch. Intern. Med. 1997, 157, 2483. [CrossRef] [PubMed]

10. Sajkov, D.; Cowie, R.J.; Thornton, A.T.; Espinoza, H.A.; McEvoy, R.D. Pulmonary hypertension and hypoxemia in obstructive sleep apnea syndrome. Am. J. Respir. Crit. Care Med. 1994, 149, 416-422. [CrossRef]

11. Krieger, J.; Sforza, E.; Apprill, M.; Lampert, E.; Weitzenblum, E.; Ratomaharo, J. Pulmonary hypertension, hypoxemia, and hypercapnia in obstructive sleep apnea patients. Chest 1989, 96, 729-737. [CrossRef] [PubMed]

12. Senaratna, C.V.; Perret, J.L.; Lodge, C.J.; Lowe, A.J.; Campbell, B.E.; Matheson, M.C.; Hamilton, G.S.; Dharmage, S.C. Prevalence of obstructive sleep apnea in the general population: A systematic review. Sleep Med. Rev. 2017, 34, 70-81. [CrossRef] [PubMed]

13. Garvey, J.F.; Pengo, M.F.; Drakatos, P.; Kent, B.D. Epidemiological aspects of obstructive sleep apnea. J. Thorac. Dis. 2015, 7, 920-929. [PubMed]

14. Punjabi, N.M. The epidemiology of adult obstructive sleep apnea. Proc. Am. Thorac. Soc. 2008, 5, 136-143. [CrossRef]

15. Peppard, P.E.; Young, T.; Barnet, J.H.; Palta, M.; Hagen, E.W.; Hla, K.M. Increased prevalence of sleep-disordered breathing in adults. Am. J. Epidemiol. 2013, 177, 1006-1014. [CrossRef] [PubMed]

16. Bibbins-Domingo, K.; Grossman, D.C.; Curry, S.J.; Davidson, K.W.; Epling, J.W.; Garcia, F.A.R.; Herzstein, J.; Kemper, A.R.; Krist, A.H.; Kurth, A.E.; et al. Screening for obstructive sleep apnea in adults us preventive services task force recommendation statement. JAMA-J. Am. Med. Assoc. 2017, 317, 407-414.

17. Lorenzi-Filho, G.; Genta, P.R.; Drager, L.F. Are we missing obstructive sleep apnea diagnosis? Rev. Port. Pneumol. (Engl. Ed.) 2017, 23, 55-56. [CrossRef] [PubMed]

18. Jun, J.C.; Chopra, S.; Schwartz, A.R. Sleep apnoea. Eur. Respir. Rev. 2016, 25, 12-18. [CrossRef]

19. Michalek-Zrabkowska, M.; Wieckiewicz, M.; Macek, P.; Gac, P.; Smardz, J.; Wojakowska, A.; Poreba, R.; Mazur, G.; Martynowicz, H. The Relationship between Simple Snoring and Sleep Bruxism: A Polysomnographic Study. Int. J. Environ. Res. Public Health 2020, 17, 8960. [CrossRef]

20. Thurtell, M.J.; Bruce, B.B.; Rye, D.B.; Newman, N.J.; Biousse, V. The Berlin questionnaire screens for obstructive sleep apnea in idiopathic intracranial hypertension. J. Neuro-Ophthalmol. 2011, 31, 316-319. [CrossRef]

21. Huang, H.H.; Lee, M.S.; Shih, Y.L.; Chu, H.C.; Huang, T.Y.; Hsieh, T.Y. Modified mallampati classification as a clinical predictor of peroral esophagogastroduodenoscopy tolerance. BMC Gastroenterol. 2011, 11. [CrossRef]

22. Gurani, S.F.; Cattaneo, P.M.; Rafaelsen, S.R.; Pedersen, M.R.; Thorn, J.J.; Pinholt, E.M. The effect of altered head and tongue posture on upper airway volume based on a validated upper airway analysis-An MRI pilot study. Orthod. Craniofacial. Res. 2020, 23, 102-109. [CrossRef] [PubMed]

23. Zhang, C.; Bruggink, R.; Baan, F.; Bronkhorst, E.; Maal, T.; He, H.; Ongkosuwito, E.M. A new segmentation algorithm for measuring CBCT images of nasal airway: A pilot study. PeerJ 2019, 2019. [CrossRef]

24. Enciso, R.; Nguyen, M.; Shigeta, Y.; Ogawa, T.; Clark, G.T. Comparison of cone-beam CT parameters and sleep questionnaires in sleep apnea patients and control subjects. Oral Surg. Oral Med. Oral Pathol. Oral Radiol. Endodontol. 2010, 109, 285-293. [CrossRef] [PubMed]

25. Nuckton, T.J.; Glidden, D.V.; Browner, W.S.; Claman, D.M. Physical examination: Mallampati score as an independent predictor of obstructive sleep apnea. Sleep 2006, 29, 903-908. [CrossRef]

26. Li, Y.; Lin, N.; Ye, J.; Chang, Q.; Han, D.; Sperry, A. Upper airway fat tissue distribution in subjects with obstructive sleep apnea and its effect on retropalatal mechanical loads. Respir. Care 2012, 57, 1098-1105. [CrossRef] [PubMed]

27. Ringhofer, C.; Lenglinger, J.; Riegler, M.; Kristo, I.; Kainz, A.; Schoppmann, S.F. Waist to hip ratio is a better predictor of esophageal acid exposure than body mass index. Neurogastroenterol. Motil. 2017, 29. [CrossRef]

28. Zimmerman, J.N.; Lee, J.; Pliska, B.T. Reliability of upper pharyngeal airway assessment using dental CBCT: A systematic review. Eur. J. Orthod. 2017, 39, 489-496. [CrossRef]

29. Mouhanna-Fattal, C.; Papadopoulos, M.; Bouserhal, J.; Tauk, A.; Bassil-Nassif, N.; Athanasiou, A. Evaluation of upper airway volume and craniofacial volumetric structures in obstructive sleep apnoea adults: A descriptive CBCT study. Int. Orthod. 2019, 17. [CrossRef]

30. Barrera, J.E.; Pau, C.Y.; Forest, V.-I.; Holbrook, A.B.; Popelka, G.R. Anatomic measures of upper airway structures in obstructive sleep apnea. World J. Otorhinolaryngol.—Head Neck Surg. 2017, 3, 85-91. [CrossRef]

31. Buchanan, A.; Cohen, R.; Looney, S.; Kalathingal, S.; De Rossi, S. Cone-beam CT analysis of patients with obstructive sleep apnea compared to normal controls. Imaging Sci. Dent. 2016, 46, 9-16. [CrossRef] [PubMed]

32. Chiu, H.Y.; Chen, P.Y.; Chuang, L.P.; Chen, N.H.; Tu, Y.K.; Hsieh, Y.J.; Wang, Y.C.; Guilleminault, C. Diagnostic accuracy of the Berlin questionnaire, STOP-BANG, STOP, and Epworth sleepiness scale in detecting obstructive sleep apnea: A bivariate meta-analysis. Sleep Med. Rev. 2017, 36, 57-70. [CrossRef] [PubMed]

33. Yucel, A.; Unlu, M.; Haktanir, A.; Acar, M.; Fidan, F. Evaluation of the upper airway cross-sectional area changes in different degrees of severity of obstructive sleep apnea syndrome: Cephalometric and dynamic CT study. Am. J. Neuroradiol. 2005, 26, 2624-2629. [PubMed] 
34. Parsi, G.K.; Alsulaiman, A.A.; Kotak, B.; Mehra, P.; Will, L.A.; Motro, M. Volumetric changes of the upper airway following maxillary and mandibular advancement using cone beam computed tomography. Int. J. Oral Maxillofac. Surg. 2019, 48, 203-210. [CrossRef]

35. Mattos, C.T.; Cruz, C.V.; Da Matta, T.C.S.; Pereira, L.D.A.; Solon-De-Mello, P.D.A.; Ruellas, A.C.D.O.; Sant'Anna, E.F. Reliability of upper airway linear, area, and volumetric measurements in cone-beam computed tomography. Am. J. Orthod. Dentofac. Orthop. 2014, 145, 188-197. [CrossRef]

36. Chaudhry, U.; Cohen, J.R.; Al-Samawi, Y. Use of cone beam computed tomography imaging for airway measurement to predict obstructive sleep apnea. Cranio 2020, 1-7. [CrossRef] 